\title{
POSTOPERATIVE POTASSIUM DEFICIT AND METABOLIC ALKALOSIS. THE PATHOGENIC SIGNIFICANCE OF OPERATIVE TRAUMA AND OF POTASSIUM AND PHOSPHORUS DEPRIVATION ${ }^{1}$
}

\author{
By LEONARD P. ELIEL, 2,3 OLOF H. PEARSON, 2 AND \\ FREDERICK C. WHITE *

\begin{abstract}
(From the Division of Clinical Investigation, Sloan-Kettering Institute, Memorial Center for Cancer and Allied Diseases, New York City)
\end{abstract}

(Submitted for publication December 6, 1951; accepted February 11, 1952)

Patients maintained postoperatively on parenteral fluids or a dietary intake low or lacking in potassium may develop a syndrome characterized by apathy, lethargy, muscular weakness, abdominal distension and ileus, cardiac arrhythmias and edema; and occasionally by confusion, delirium, muscular twitching and tetany. A clinical description of the syndrome as observed in 32 postoperative patients has appeared elsewhere (1). Evidence was found in these patients for the existence of potassium deficit, namely: 1) the presence of hypopotassemia, hypochloremia and metabolic alkalosis, 2) electrocardiographic changes consistent with potassium deficit, 3 ) extensive expansion of the radiosodium space beyond the confines of the bromide space, suggesting that sodium had migrated into the cells to replace lost potassium, 4) lowering of erythrocyte potassium and increase of erythrocyte sodium concentrations in several patients, and 5) prompt reversal of the clinical and blood chemical abnormalities upon administration of adequate amounts of potassium.

Two factors were thought to be of primary importance in the pathogenesis of the potassium deficit in the group studied: 1 ) adrenal cortical hyperfunction resulting from trauma ("alarm reaction") and leading to increased renal excretion of potassium and 2) a low potassium intake with poor renal conservation of potassium. The first factor

\footnotetext{
1 This study was supported by grants from the National Cancer Institute of the Public Health Service C-925 (C2); jointly by the Office of Naval Research Contract no. N8onr-66801, and the Atomic Energy Commission, and by a grant from the American Cancer Society.

2 Damon Runyon Senior Clinical Research Fellow.

3 Present address: Oklahoma Medical Research Institute, Oklahoma City 4, Oklahoma.

- Research Fellow in the Sloan-Kettering Institute.
}

was suggested by the fact that muscular weakness, hypopotassemia, hypochloremia, and metabolic alkalosis are often observed in patients with Cushing's syndrome or in patients receiving ACTH (adrenocorticotropic hormone) or cortisone (1, 2 ); the second by the fact that all the postoperative patients but one were on a low potassium intake when the syndrome developed.

The two studies described in this paper were undertaken to evaluate the relative roles of low potassium intake and operative trauma in the production of the syndrome. Adrenal cortical hyperfunction, as estimated by several criteria, developed following the operative trauma in each case but was not separately evaluated in these studies. Hyperadrenocortical states have been induced in patients with neoplastic and other diseases by administration of adrenocorticotropic hormone (ACTH) or cortisone (11-dehydro-17-hydroxycorticosterone); and the resulting metabolic effects have been reported in detail $(2-4)$.

The first study (case 1, N. M.) was designed to reproduce approximately the conditions under which the syndrome had been observed to develop, namely, simultaneous deprivation at the time of operation of potassium and phosphorus. These elements were later restored one at a time. In the second study (case 2, M. B.) a period of potassium and phosphorus deprivation was imposed preoperatively, while the operation was performed during a period when these elements were provided in adequate amounts. Both patients underwent major surgery for suspected or proved neoplasms.5

5 We are indebted to Dr. Gordon McNeer and the Gastric and Mixed Tumor Service of Memorial Center, for the opportunity to study these patients. 


\section{MATERIALS AND METHODS}

Intravenous infusions were used exclusively except that tap water was permitted ad libitum by mouth. The parenteral fluids consisted of 1,000 cc. $10 \%$ amino acids solution, $2,000 \mathrm{cc}$. $15 \%$ dextrose solution in distilled water, and 500 cc. $10 \%$ dextrose solution in physiologic saline, daily. To the $15 \%$ dextrose solution were added four ampules of buffered potassium phosphate solution, ${ }^{7}$ and vitamins. ${ }^{8}$ In case $1,500 \mathrm{cc}$. of the amino acids solution were run in alternately with 1,000 cc. of $15 \%$ dextrose. In case 2 , the solutions were infused simultaneously through a common needle, the flows being regulated so that all bottles would empty at approximately the same time.

Each bottle of solution was weighed to the nearest 0.5 gm., before and after infusion. Weights were converted to volume and the nitrogen, glucose, and electrolyte intakes calculated using analytical values found in our laboratory. The average time for administration of the fluids was 10 hours, during which the patient was kept in bed. The patients were otherwise ambulatory and took an approximately uniform amount of exercise before and after the infusions except on the operative day and subsequent two or three days when movement was limited by pain. They arose, however, on the first postoperative day for weighing and "dangling," and thereafter became ambulatory.

Feces from the preoperative and postoperative periods were pooled separately, carmine being used to mark the termination of each period. Feces were very small in volume and had to be obtained by distilled water enemas. Any changes in fecal excretion are probably, therefore, of doubtful significance. Stool chloride analyses were omitted in the second study. All vomitus and gastrointestinal fluids were collected and analyzed. Wound drainage was collected in a small bottle firmly taped to the draining orifice and likewise analyzed.

The total intake and output of calcium, phosphorus, nitrogen, potassium, sodium and chloride were determined by methods previously described (5). Gastrointestinal fluids and wound drainage were treated in the same manner as diets and feces. The methods used in the analyses of muscle tissue and erythrocytes; of serum sodium, potassium, magnesium, chloride, calcium, phosphorus, total protein, carbon dioxide content, and $\mathrm{pH}$; of blood glucose ; and of urinary creatine, creatinine, uric acid, glucose, and

- Provided through the generosity of $\mathrm{Dr}$. Augustus Gibson, Merck \& Co., Rahway, New Jersey.

' Provided through the generosity of Abbott Laboratories, North Chicago, Illinois. Each ampule contained $\mathrm{K}_{2} \mathrm{HPO}_{4}\left(1.55 \mathrm{gm}\right.$.) and $\mathrm{KH}_{2} \mathrm{PO}_{4}(0.30 \mathrm{gm}$.), providing 20 milliequivalents of potassium and $0.342 \mathrm{gm}$. of phosphorus.

8 Thiamin $5 \mathrm{mg}$., niacin $50 \mathrm{mg}$., calcium pantothenate 5 mg., pyridoxine $5 \mathrm{mg}$., riboflavin $2 \mathrm{mg}$., vitamin $B_{\mathfrak{z}}$ ( 30 gamma every three days), ascorbic acid $500 \mathrm{mg}$., and 2methyl naphthoquinone $2.4 \mathrm{mg}$. steroids ${ }^{\circ}$ have been described elsewhere $(1,5)$, as have methods for performing dilution studies with radioactive sodium $\left(\mathrm{Na}^{\mathrm{m}}\right)$ and bromide. The radiosodium and bromide spaces were determined at intervals of four and $51 / 2$ hours after the initial infusion. The sodium and chloride content of the spaces was calculated assuming that bromide ion has the same distribution as chloride (6). Blood urea nitrogen was determined by the method of Van Slyke and Plazin (7).

A muscle biopsy was taken from the rectus abdominis immediately after the initial operative incision in case 1 . A repeat biopsy from the pectoral muscle was performed on the 11th postoperative day. Tissue water and electrolyte distributions (Table II) were computed assuming that chloride occupies an extracellular position. The possible inaccuracy of such an assumption is recognized, but it does provide a reasonable, if only approximate, description of water and electrolyte shifts.

All analyses were performed in duplicate.

Theoretical weight curves (Figures 3 and 7) were computed by the method of Reifenstein, Albright, and Wells (8). Intracellular balances of sodium, potassium, and phosphorus (Figures 9,11 and Table I) were calculated in the manner described by Bartter and associates (9), except that in case 1 the ratios, $K / \mathrm{N}=2.9$ and $\mathrm{P} / \mathrm{N}$ $=.054$, were derived from the patient's first muscle biopsy (Table II) ; and in case 2 , the ratios, $\mathrm{K} / \mathrm{N}=2.8$ and $\mathrm{P} / \mathrm{N}=.064$, were derived from the means of muscle analyses in five chronically ill hospital patients who had no evidence of electrolyte disturbance (4). In computing intracellular balances, corrections for insensible skin losses were made by subtracting algebraically the average of the control period balances from the found balance values.

\section{DESCRIPTION OF CASES}

Case 1 (N.M.) No. 95379. A 71 year old man was admitted to the metabolic ward three weeks after a cholecystojejunostomy for obstructive jaundice due to a mass in the head of the pancreas. Examination showed the patient to be well nourished. The jaundice had subsided. He was placed on complete parenteral feedings. After eight days on this regime a duodenectomy, partial pancreatectomy, partial gastrectomy, pancreatico-jejunostomy, choledochojejunostomy, and liver biopsy were performed under nitrous oxide-ether anesthesia. A $2 \mathrm{~cm}$. mass was found in the region of the ampulla, which proved to be carcinoma on pathological examination. The duration of the operation was six hours. The patient was never in shock. Fifteen hundred $\mathrm{cc}$. of citrated whole blood, estimated to replace operative blood losses, were administered intravenously during the operation.

Postoperatively, potassium phosphate was omitted from the parenteral feedings. Potassium chloride 10 was added on the ninth postoperative day and was replaced by potassium phosphate in equivalent amounts on the 12th day.

- Urinary ketosteroids, formaldehydogenic steroids and reducing steroids were determined in the laboratory of Dr. Konrad Dobriner.

10 Potassium chloride solution in ampules was provided through the generosity of Abbott Laboratories. 


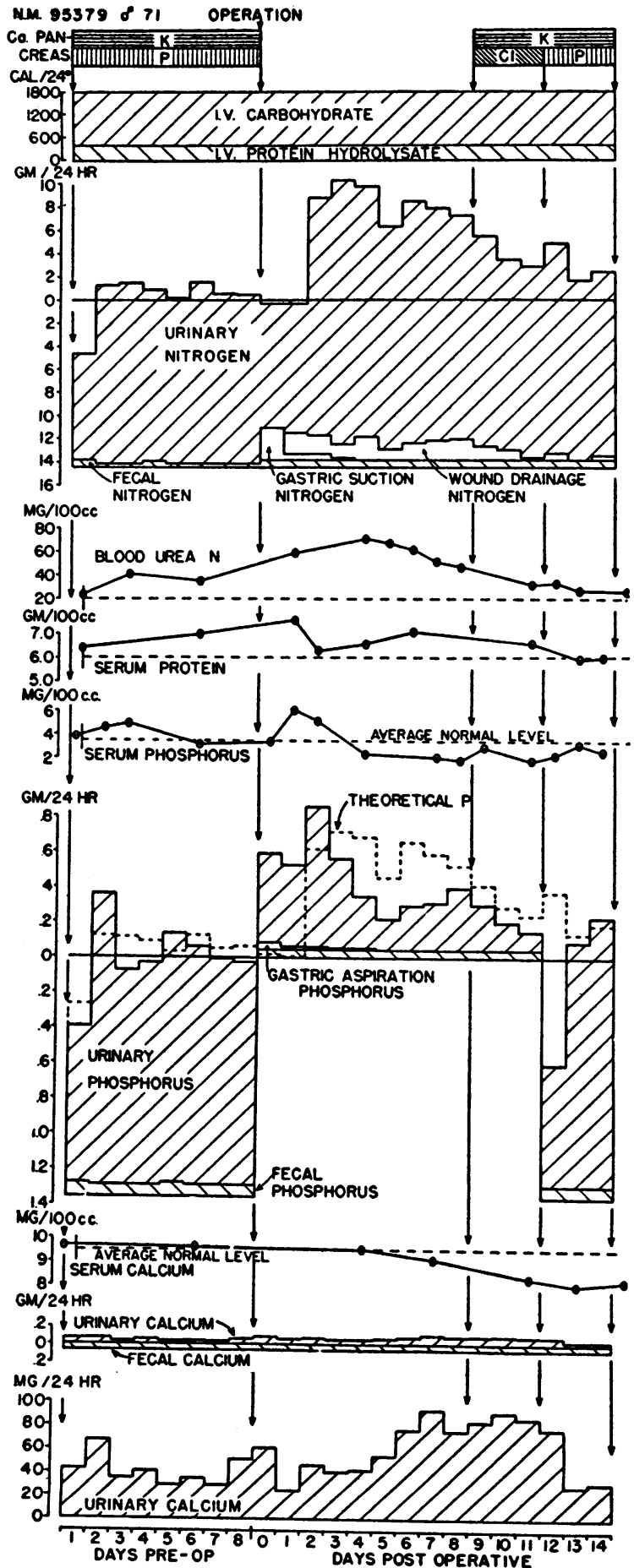

Fig. 1. Case 1. The Effects of Operative Trauma on the Nitrogen, Phosphorus, and Calctum Balances; on the Serum Total Protein, Phosphorus, and Calcium Concentrations; on the Blood Urea Nitrogen Concentration; and on thr Urinary Calcium ExCRETION
The patient remained in good condition throughout the postoperative period. A nasogastric tube was left in place two days. Except on the operative day, the gastrointestinal fluid losses were small. Wound drainage was remarkably scanty, no fistula developed, and wound healing proceeded satisfactorily. Peristalsis was present on the third day, but on the fourth day he felt very tired and was drowsy. On the eighth day some abdominal distension was noted. Improvement in the tiredness, drowsiness and abdominal distension occurred when potassium was provided. Rectal temperatures with daily maximums of $100.5^{\circ}-102^{\circ} \mathrm{F}$. occurred postoperatively for which no cause was found and which persisted in spite of administration of penicillin and streptomycin. The fever subsided abruptly at the time antibiotics were discontinued on the 12th postoperative day.

The blood chemical findings during the balance study are charted in Figures 1 to 4. The serum calcium fell postoperatively, but the calculated serum ionized calcium concentration remained essentially constant due to a fall in serum protein concentration. The serum magnesium rose slightly postoperatively, then fell, but remained within the normal range. The blood urea nitrogen rose postoperatively, reaching $71.6 \mathrm{mg} . / 100 \mathrm{cc}$. on the fourth postoperative day, then subsided gradually to control period values.

The electrocardiogram, which was normal preoperatively, showed slight lowering of $T$ waves in all leads and depression of RT segments on the first postoperative day. On subsequent tracings (fourth to ninth days) these changes became more pronounced, the QT interval became prolonged and numerous premature ventricular contractions appeared. All of the abnormalities were corrected upon provision of potassium.

The packed red cell volume was $37 \%$ preoperatively, $44 \%$ immediately postoperatively and gradually fell to $28 \%$ on the day the study was terminated.

Case 2 (M. B.) No. 98585. A 55 year old woman developed, six weeks before entry, epigastric pain, nausea, vomiting and, on two occasions, hematemesis. A gastric

\section{Fic. 1. (Continued)}

The balance charts are constructed by plotting the intake downwards from the zero line and by plotting upwards from the intake, first the fecal, then the urinary excretions. If the sum of the excretions coincides with the zero line, balance is indicated; if it rises above, the balance is negative; and if it falls below, leaving a clear space, the balance is positive. The ordinates of the nitrogen, phosphorus, and calcium charts are so chosen that equal heights represent the approximate ratios at which these elements exist in normal protoplasm and bone; that is, $15 \mathrm{gm}$. of nitrogen to $1 \mathrm{gm}$. of phosphorus (protoplasm), and $2 \mathrm{gm}$. of calcium to $1 \mathrm{gm}$. of phosphorus (bone). The sum of the nitrogen and calcium balances gives the theoretical phosphorus balance (broken line); that is, the phosphorus balance that would be predicted from changes in protoplasm based on nitrogen, plus changes in bone based on calcium. 
TABLE I

Intracellular balances of potassium, phosphorus, and sodium in case 1

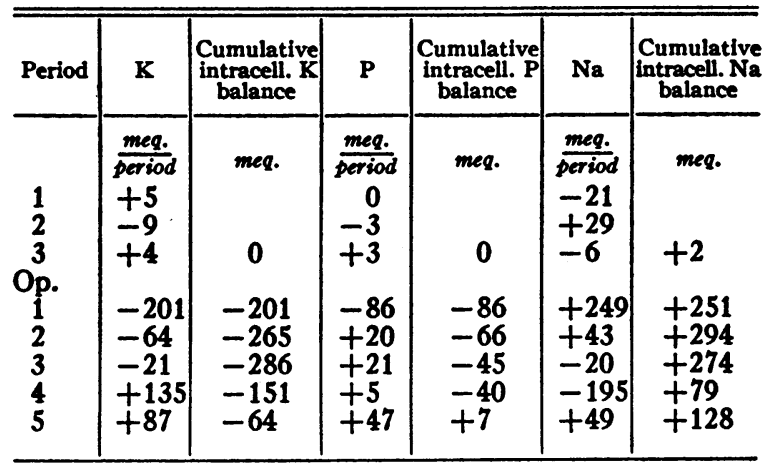

ulcer was demonstrated radiographically and the patient was admitted for surgical exploration. Examination was normal except for some epigastric tenderness. She was placed on complete parenteral feedings. From the fifth to the eighth days, inclusive, potassium and phosphate ions were omitted. On the sixth day she complained of weakness and increased intestinal gas. Decreased peristalsis was noted on the eighth day. From the ninth day to the end of the study, potassium and phosphate ions were restored. On the tenth day the patient felt stronger and peristaltic sounds were more numerous. On the 13th day a sub-total gastrectomy was performed under nitrous oxide-ether anesthesia. A benign gastric ulcer was found. The operation lasted $41 / 2$ hours. The patient was not in shock at any time. She received $500 \mathrm{cc}$. of citrated whole blood during the operation. During the first two postoperative days there was moderate nausea, vomiting, abdominal distension, and a maximum rectal temperature of $100.2^{\circ} \mathrm{F}$., but her postoperative course was uneventful thereafter.

The serum chemistries are charted in Figures 5 to 8 . The serum calcium fell substantially after surgery, but the calculated ionized calcium remained essentially constant due to a fall in serum total protein concentration.
No significant changes occurred in the electrocardiogram. No tissue analyses or dilution studies were done.

There was no significant change in the packed volume of erythrocytes.

\section{EXPERIMENTAL RESULTS}

Case 1 (N.M.)

Approximate equilibrium with respect to nitrogen and the electrolytes was observed during the preoperative period. No nitrogen loss occurred until the second postoperative day (Figure 1). However the blood urea nitrogen increased by $37 \mathrm{mg} . / 100 \mathrm{cc}$. during the first five post-operative days (Figure 1), a rise which could account for $10.6 \mathrm{gm}$. of retained nitrogen. ${ }^{11}$ On the second and third postoperative days, however, there was a markedly negative nitrogen balance, following which the urinary nitrogen losses diminished gradually. A coincident gradual fall in the blood urea nitrogen occurred. A slightly more rapid fall in urinary nitrogen was noted after provision of potassium chloride.

A large loss of phosphorus (Figure 1) in excess of that predicted from the calcium and nitrogen balances (broken line) occurred during the operative and first two postoperative days, suggesting loss of phosphorus from intracellular fluid (see also Figure 9 and Table I). This was followed by a period when more phosphorus was retained than would be predicted, suggesting that destruction of protoplasm was providing sufficient phosphorus to repair the deficit. When phosphate ion was added on the 12th postoperative day, retention of phosphorus occurred for only one day,

11 Assuming body water to be 28.6 liters (53\% body weight [10]) and urea to be distributed evenly therein.

TABLE II

Muscle and erythrocyte analyses at operation and 11 days postoperatively in case 1

\begin{tabular}{|c|c|c|c|c|c|c|c|c|c|c|c|c|c|}
\hline \multirow{2}{*}{ Day } & \multirow{2}{*}{ Tissue } & \multicolumn{5}{|c|}{ Found values* } & \multicolumn{4}{|c|}{ Derived data } & \multicolumn{3}{|c|}{ Water distribution $\ddagger$} \\
\hline & & {$[\mathbf{K}]_{\mathbf{k}}$} & {$[\mathbf{N a}]_{\mathbf{t}}$} & {$[\mathrm{Cl}]_{\mathbf{k}}$} & {$[\mathbf{N}]_{\mathbf{t}}$} & {$[\mathbf{P}]_{\mathbf{t}}$} & {$[\mathbf{K}]_{\mathbf{i}}$} & $(\mathbf{K})_{\mathbf{l}}$ & {$[\mathrm{Na}]_{\mathbf{l}}$} & $(\mathrm{Na})_{\mathbf{i}}$ & $\left(\mathrm{H}_{2} \mathrm{O}\right)_{\mathbf{t}}$ & $(\mathrm{H}, \mathrm{O})_{\bullet}$ & $(\mathrm{H}, 0)_{i}$ \\
\hline $\begin{array}{r}0 \\
11\end{array}$ & $\begin{array}{l}\text { Muscle } \\
\text { Muscle }\end{array}$ & $\begin{array}{c}\text { meq. } \\
437.3 \\
258.8\end{array}$ & $\begin{array}{c}\text { meg. } \\
163.6 \\
161.3\end{array}$ & $\begin{array}{r}\text { meq. } \\
98.3 \\
116.5\end{array}$ & $\begin{array}{c}\mathrm{sm} . \\
134.4 \\
141.3\end{array}$ & $\begin{array}{l}8 m . \\
7.24 \\
7.69\end{array}$ & $\begin{array}{l}\text { meq.* } \\
433.8 \\
255.2\end{array}$ & $\begin{array}{c}\text { mee. } \\
148.8 \\
122.4\end{array}$ & $\begin{array}{l}\text { meq.* } \\
43.0 \\
10.3\end{array}$ & $\begin{array}{r}\text { meq.t } \\
14.7 \\
4.9\end{array}$ & $\begin{array}{l}8 m . \\
791 \\
759\end{array}$ & $\begin{array}{l}8 \mathrm{sm} . \\
177 \\
249\end{array}$ & $\begin{array}{l}8 m . \\
614 \\
510\end{array}$ \\
\hline $\begin{array}{r}0 \\
11\end{array}$ & $\begin{array}{l}\text { Erythrocytes } \\
\text { Erythrocytes }\end{array}$ & $\begin{array}{r}108.6 \\
86.0\end{array}$ & 9.0 & $\begin{array}{l}81.6 \\
73.6\end{array}$ & & & & & & & & & \\
\hline
\end{tabular}

Subscripts t, i, e, signify total tissue, intracellular and extracellular, respectively.

* Per kilogram dry, fat-free muscle or per liter packed erythrocytes.

$\dagger$ Per kilogram of intracellular water.

$\ddagger$ Per kilogram wet, fat-free tissue. 
suggesting that the intracellular deficit had been largely repaired. This interpretation is confirmed by the analysis of muscle tissue, taken one day before phosphorus was started, which shows essentially no change in the phosphorus content (Table II). The extracellular phosphorus concentration fell to abnormally low levels, a fall which was more than could be accounted for by the apparent expansion in extracellular fluid which occurred simultaneously (see below). The hypophosphatemia was corrected following provision of phosphate ion.

The urinary calcium excretion (Figure 1) rose during the period of phosphate deprivation, falling to control period levels only on the second day of phosphate readministration. Thus, as a result of increased bone destruction, a small amount of phosphorus (equivalent to the increase in negative calcium balance in Figure 1) was made available for reduction and repair of intracellular phosphorus losses. When the theoretical phosphorus balance finally coincided with the actual, indicating tissue repletion, the urinary calcium excretion fell to its control period values.

The potassium balance (Figure 2), like the phosphorus balance, shows postoperatively, large losses in excess of those predicted from the nitrogen balance (broken line), suggesting intracellular depletion. This is also shown by the calculated intracellular balances (Table I and Figure 9) and is confirmed by the postoperative muscle analysis (Table II) which shows a drop of $178.6 \mathrm{meq} . / \mathrm{kg}$. of dry, fat-free tissue. From such a marked drop one would have anticipated an intracellular deficit of around 700 meq. ${ }^{12}$ instead of the 151 to 286 meq. predicted from the balance data (Table I). Two explanations for the discrepancy are suggested: 1 ) The patient's muscles were found to be extraordinarily thin at both biopsies and large areas had to be excised to obtain sufficient tissue. A low muscle mass was also suggested by the creatinine excretion which averaged only $17.8 \mathrm{mg} . / \mathrm{kg}$./day during the control period. The smaller the muscle mass the larger would be the fall in its potassium content, per unit weight, produced by a given potassium loss. 2) A transfer of potassium from muscle to liver glycogen may have occurred, as

\footnotetext{
12 Calculated using muscle analyses (Table II), and assuming that the muscle mass is $41 \%$ of body weight (11), and that other tissues were not significantly depleted.
}

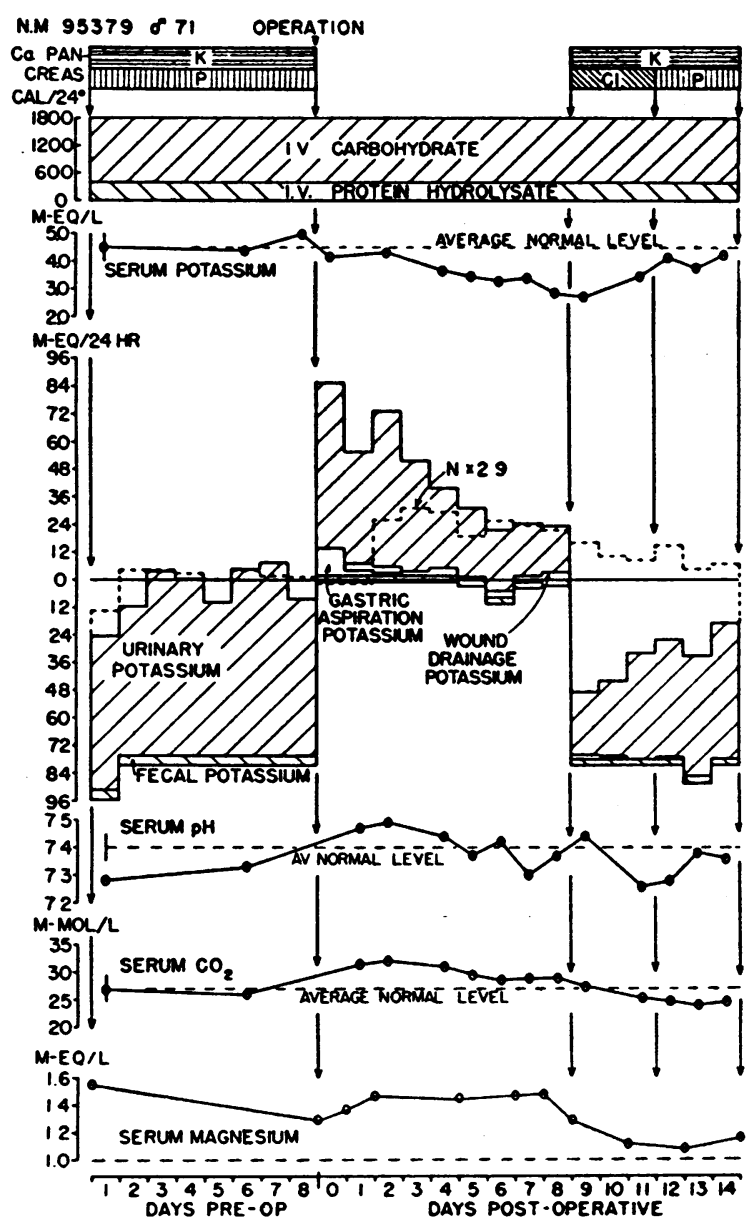

Fig. 2. Case 1. The Effects of Operative Trauya and Potassium and Chloride Deprivation on the Potassium Balance; on the Serum Potassium axd Magnesium Concentrations; and on the Sraum Carbon Dioxide Content and pH

suggested by Bartter and associates from observations on patients receiving adrenocorticotropic hormone (9).

The tissue analyses (Table II) demonstrated, in addition to a marked potassium depletion postoperatively, a shift of water from the intracellular to the extracellular compartment which in effect would tend to preserve the concentration of intracellular potassium. The failure to find increased tissue sodium associated with potassium deficit (Table II) may be explained by the fact that at the time the biopsy was taken (11th day, postoperative period 4 ), $73 \%$ of the previously accumulated intracellular sodium had been extruded. 
The sodium space determined on the eighth postoperative day, period 3 (Figure 10), showed a marked extension over preoperative values. Its sodium content exceeded by 270 meq. the amount which could be accounted for in the bromide space (broken line), suggesting either intracellular migration of sodium or increased exchangeability of intracellular sodium. The former interpretation appears more likely, since the loss of intracellular potassium (286 meq.) and gain of intracellular sodium (274 meq.) calculated from the balance data at this time (Table I) fit with admirable precision the increase in intracellular sodium suggested by the dilution studies.

Unlike the phosphorus deficit, no repair of the intracellular potassium deficit occurred until potassium was provided. A pronounced fall in extracellular fluid potassium concentration occurred postoperatively, which could not be accounted for by extracellular fluid expansion. This was accompanied by the development of metabolic alkalosis which, however, subsided spontaneously. Addition of potassium resulted in prompt correction of the hypopotassemia and a further fall in the serum $\mathrm{pH}$ and carbon dioxide content. Dilution studies on the 15 th postoperative day (Figure 10) also demonstrated a marked reduction of intracellular sodium (area above broken line), suggesting extrusion of sodium when potassium was provided.

The chloride balance (Figure 3 ) shows a marked rise in urinary chloride excretion on the operative day. Losses from gastric aspiration contributed to a large negative balance. The sodium balance on the operative day, although negative, shows a retention relative to chloride (broken line). The balance data indicate that the chloride loss was made up by the fifth postoperative day and that further retention occurred thereafter. The latter is confirmed by the dilution studies (Figure 10), which demonstrated on the eighth postoperative day an increase in the chloride content of the bromide space of about 300 meq. These data suggest that the metabolic alkalosis was at least partially corrected by repair of the chloride deficit and that further retention of sodium and chloride then occurred, resulting in expansion of extracellular fluid volume. The expansion of the sodium and chloride spaces also indicates that the increased retention of sodium and chloride shown by the balance data was not an apparent one due to insensible skin losses.

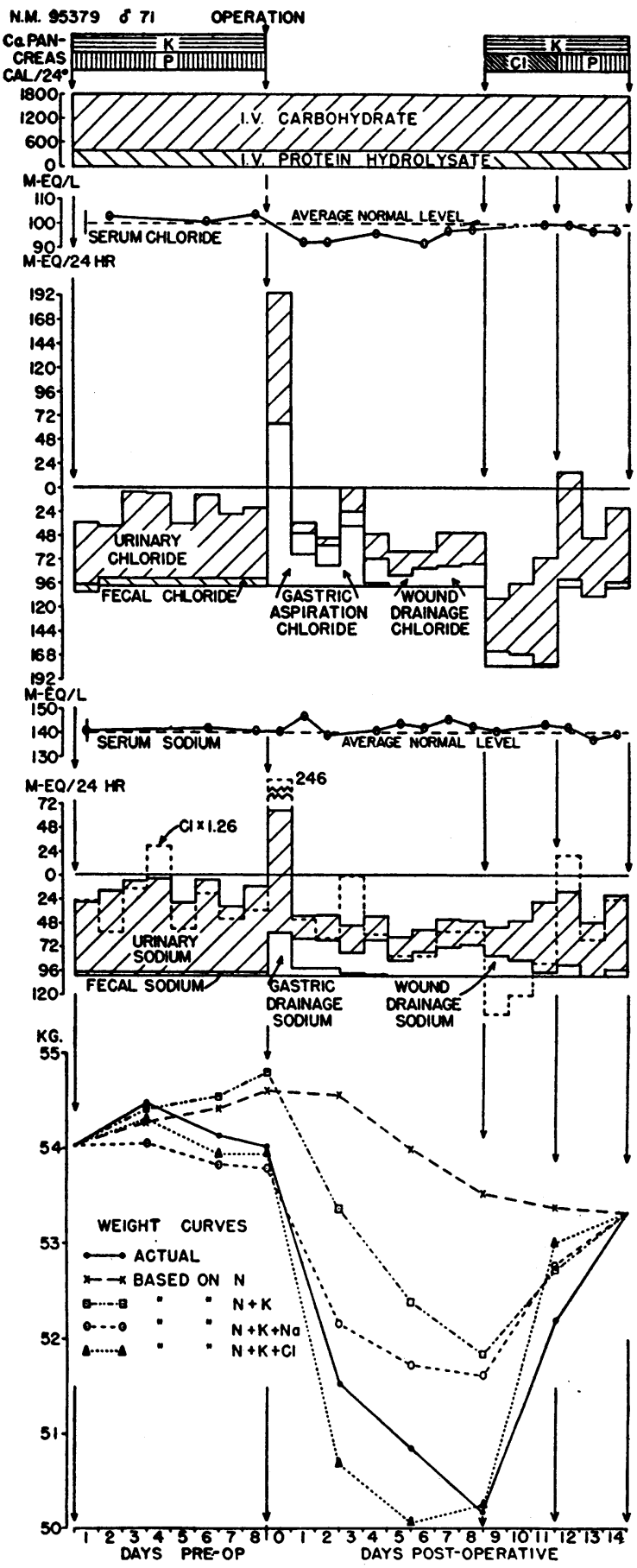

Fig. 3. Case 1. The Effects of Operative Trauma and Potassium and Chloride Deprivation on the Chloride and Sodium Balances; on the Serum Chloride and Sodium Concentrations; and on the Actual and Theoretical Weight Curves

The broken line on the sodium balance $(\mathrm{Cl} \times 1.26)$ represents the sodium balance that would be expected if sodium were excreted in the same ratio to chloride as exists normally in extracellular water. 
The theoretical weight curves (Figure 3 ) demonstrate that the actual weight changes are most closely approximated by a curve combining estimated changes in protoplasm, intracellular and extracellular fluids as calculated, respectively, from the nitrogen, potassium, and chloride balances $(\mathrm{N}+\mathrm{K}+\mathrm{Cl})$. The curve which utilizes sodium instead of chloride $(\mathrm{N}+\mathrm{K}+\mathrm{Na})$ predicts a smaller weight loss postoperatively, thus demon-

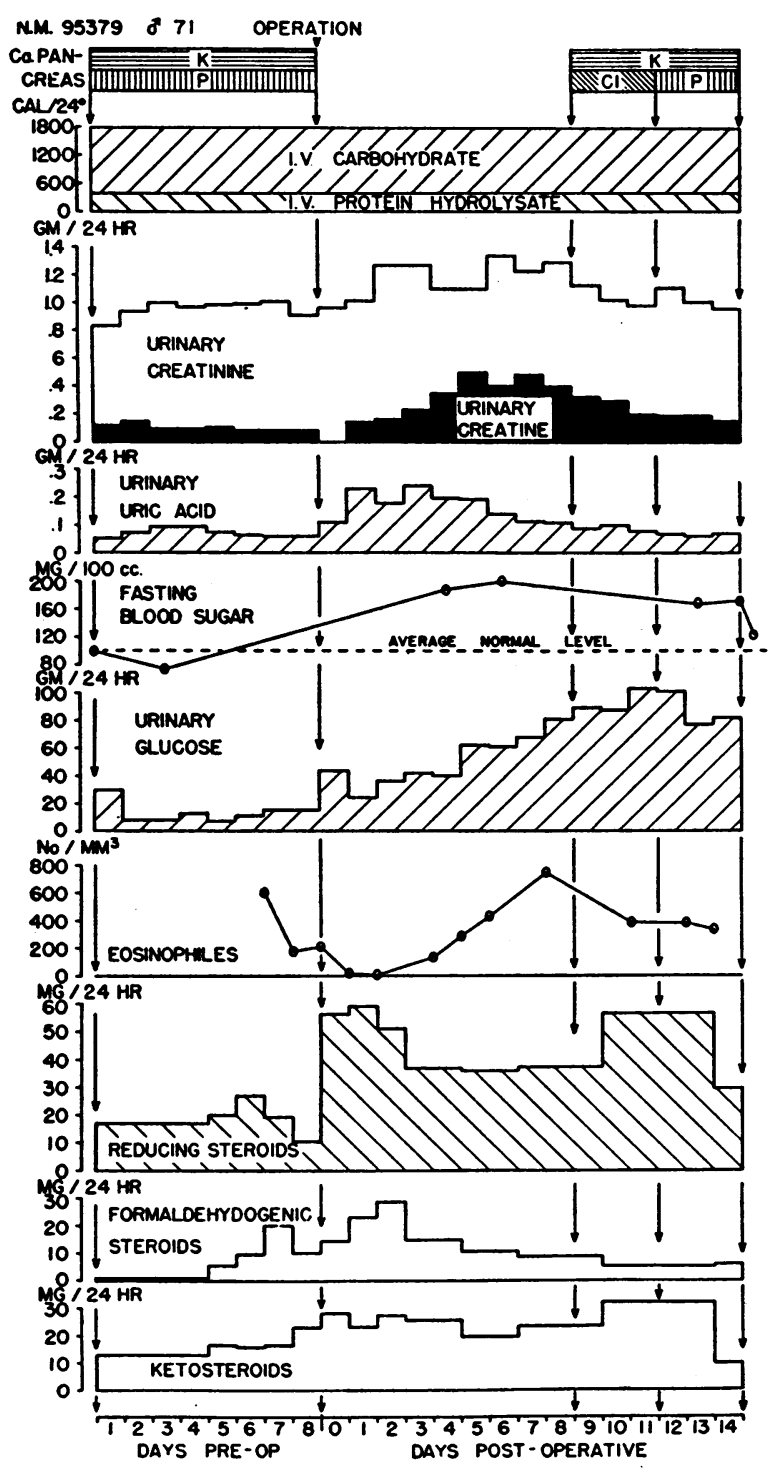

Fig. 4. Case 1. The Effects of Operative Trauma and Potassium and Phosphorus Deprivation on the Urinary Creatine, Creatinine, Uric Acid, Glucose, Reducing Steroid, Formaldehydogenic Steroid, and Ketosteroid Excretion; and on the Fasting Blood Glucose and Eosinophile Concentrations
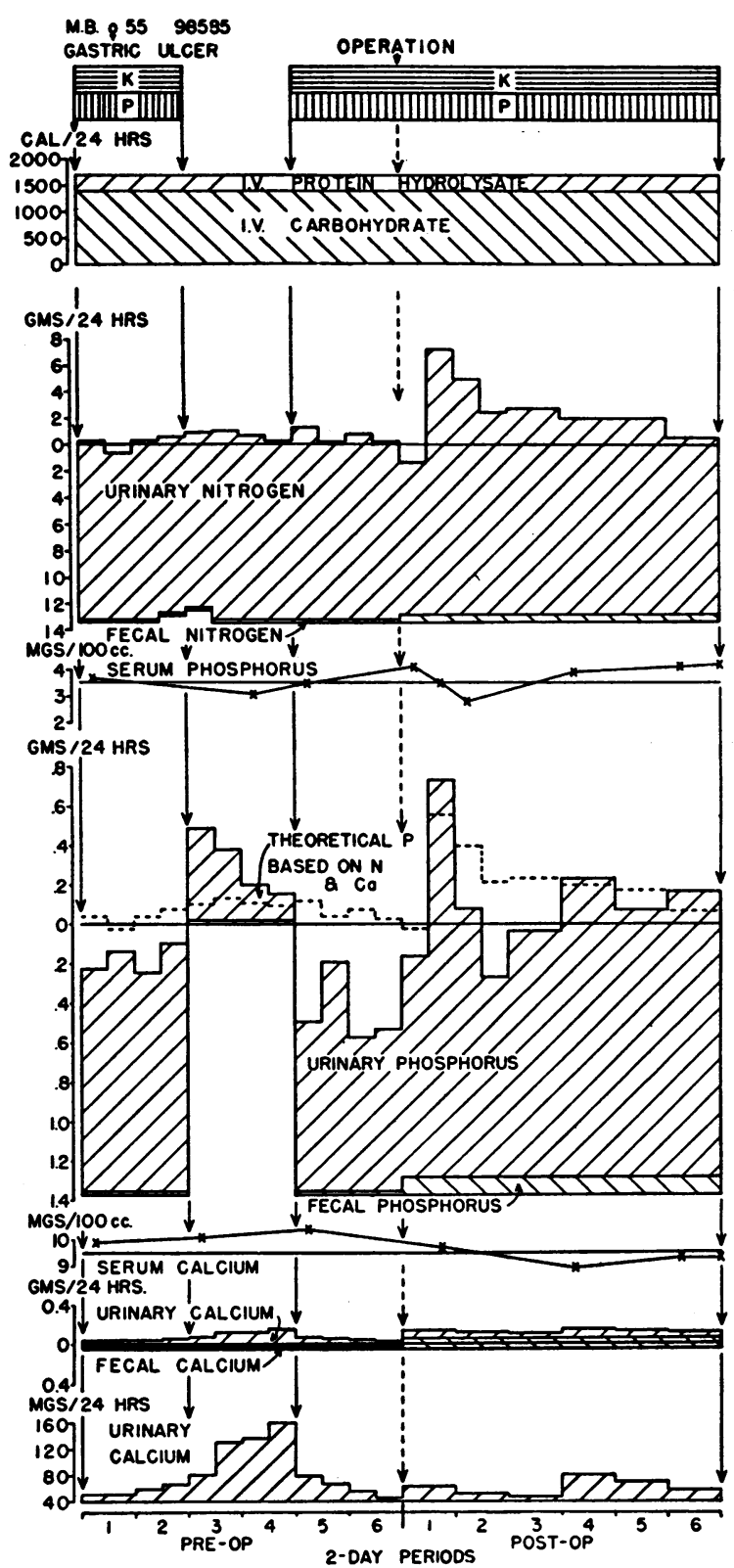

Fig. 5. Case 2. The Effects of Potassium and Phosphorus Deprivation and of Operative Trauma on the Nitrogen, Phosphorus, and Calcium Balances; on the Urinary Calcium Excretion; and on the Serum Phosphorus and Calcium Concentrations

strating again the retention of sodium relative to chloride which occurred at that time.

The urinary excretion of creatine and uric acid rose postoperatively (Figure 4). A progressive fall in urinary creatine occurred at the time that potassium chloride was restored to the intake. A progressive rise in urinary glucose occurred post- 
operatively (Figure 4) and was associated with a rise in the fasting blood glucose concentration. There is a suggestion that provision of phosphate may have resulted in slight reduction of the glycosuria during the last three days of the study. Both hyperglycemia and glycosuria disappeared promptly on cessation of parenteral feeding.

A slight increase in the urinary reducing steroids and ketosteroids occurred preoperatively (Figure 4 ), but there was a marked rise in formaldehydogenic steroids. These rises were associated with a drop in the eosinophile count from 606 to 189 cells $/ \mathrm{mm}^{3}{ }^{3}$, suggesting some increase in adrenal cortical function, the cause of which was not apparent. The circulating eosinophile count (Figure 4) fell to zero on the first two postoperative days, then rose to preoperative levels or above. Further increases in steroid excretion, particularly in the reducing steroids, were observed postoperatively.

\section{Case 2 (M. B.)}

During the initial control period the patient was in nitrogen equilibrium (Figure 5). No significant rise in nitrogen excretion occurred during the period of potassium and phosphate deprivation. Postoperatively, the nitrogen excretion rose, resulting in a negative balance of $7.2 \mathrm{gm}$. on the first postoperative day, and remained elevated until the tenth postoperative day (period 5).

When phosphate was omitted preoperatively, a prompt negative phosphorus balance resulted and there was a slight fall in serum phosphorus concentration. Intracellular depletion of phosphorus is indicated by $a$ ) phosphorus loss in excess of the theoretical balance (Figure 5 , broken line), $b$ ) the calculated intracellular balance (Figure 11), and c) retention of phosphorus in excess of the theoretical when the phosphorus intake was restored (Figure 5).

During the period of phosphorus deprivation, as in case 1 , there was a marked increase in urinary calcium excretion which subsided when phosphorus was restored.

An abrupt rise in urinary phosphorus excretion occurred on the operative day, resulting in a negative balance on the first postoperative day, in slight excess of the theoretical balance. This was followed by a period of retention. A slightly nega-

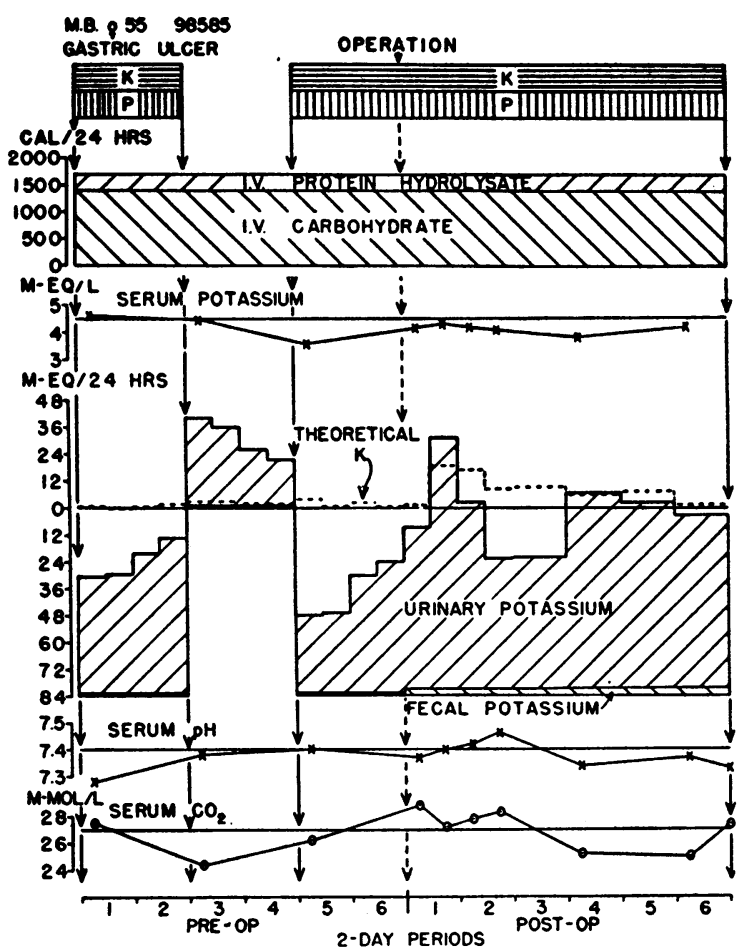

Fig. 6. Case 2. The Effects of Potassium and Phosphorus Deprivation and of Operative Trauma on the Potassium Balance, Serum Potassium Concentration, Serum Carbon Dioxide Content, and SeRUM PH

tive phosphorus balance was observed during the last six days of the study.

The potassium balance (Figure 6) closely paralleled the phosphorus balance. During potassium deprivation, there was a loss of potassium of 40.8 meq. on the first day which diminished gradually to 22.0 meq. on the last day. This loss was largely intracellular (Figure 11). A simultaneous decrease in serum potassium concentration occurred, but there was no significant change in the serum $\mathrm{pH}$ or carbon dioxide content. Marked increases in urinary potassium excretion occurred on the first two postoperative days, exceeding the theoretical balance on the first postoperative day by $15 \mathrm{meq}$. A period of potassium retention ensued, suggesting repair of a deficit. A slight decrease in serum potassium concentration and a gradual rise in serum $\mathrm{pH}$ occurred postoperatively. The carbon dioxide content did not change significantly.

Retention of sodium and chloride occurred during potassium and phosphate deprivation (Figure 


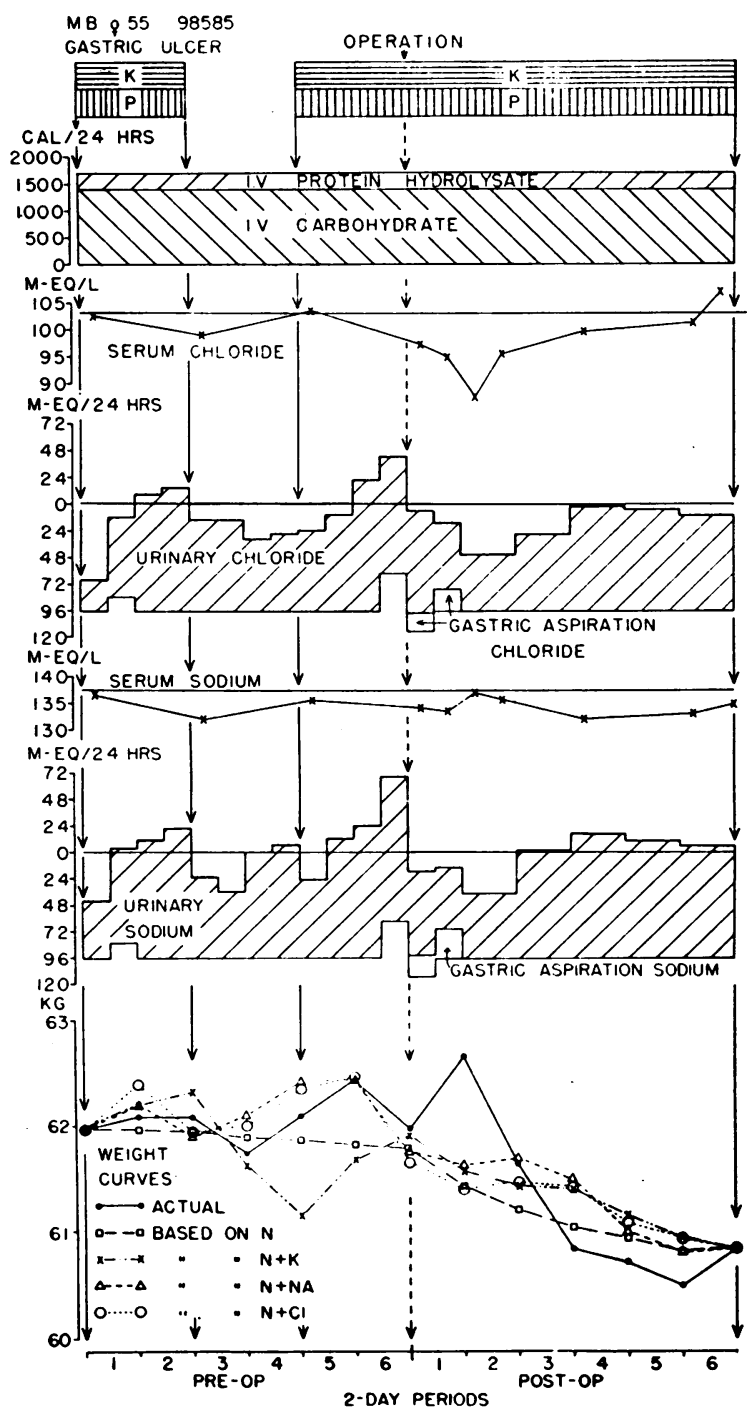

Fici. 7. Case 2. The Effects of Potassilim and Pilospiloris Deprivation and of Operative Trauma ox tile Cilloride and Sodicm Balances, on tile Seri Chloride and Sodium Concentrations: and oN the Actial. and Theoretical. Weight Cirves

7). Addition of potassium phosphate resulted in a moderate diuresis of sodium and chloride. Retention of sodium and chloride was again observed postoperatively. The intracellular balance (Figure 11) demonstrates the opposite movements across the cell membrane of sodium with respect to potassium during the period of potassium deprivation, and postoperatively.

The theoretical weight curves (Figure 7) reflect the intracellular potassium depletion and sodium and chloride retention during preoperative periods 3 and 4 .

Moderate rises in urinary creatine and uric acid occurred postoperatively (Figure 8). Urinary glucose excretion (Figure 8) was elevated at the onset of the study, reached a maximum during the period of potassium and phosphate deprivation, then subsided to essentially normal amounts, with only a slight rise occurring postoperatively. The blood glucose level (Figure 8) fluctuated within normal limits. Circulating eosinophiles fell to zero on the first two postoperative days coin-

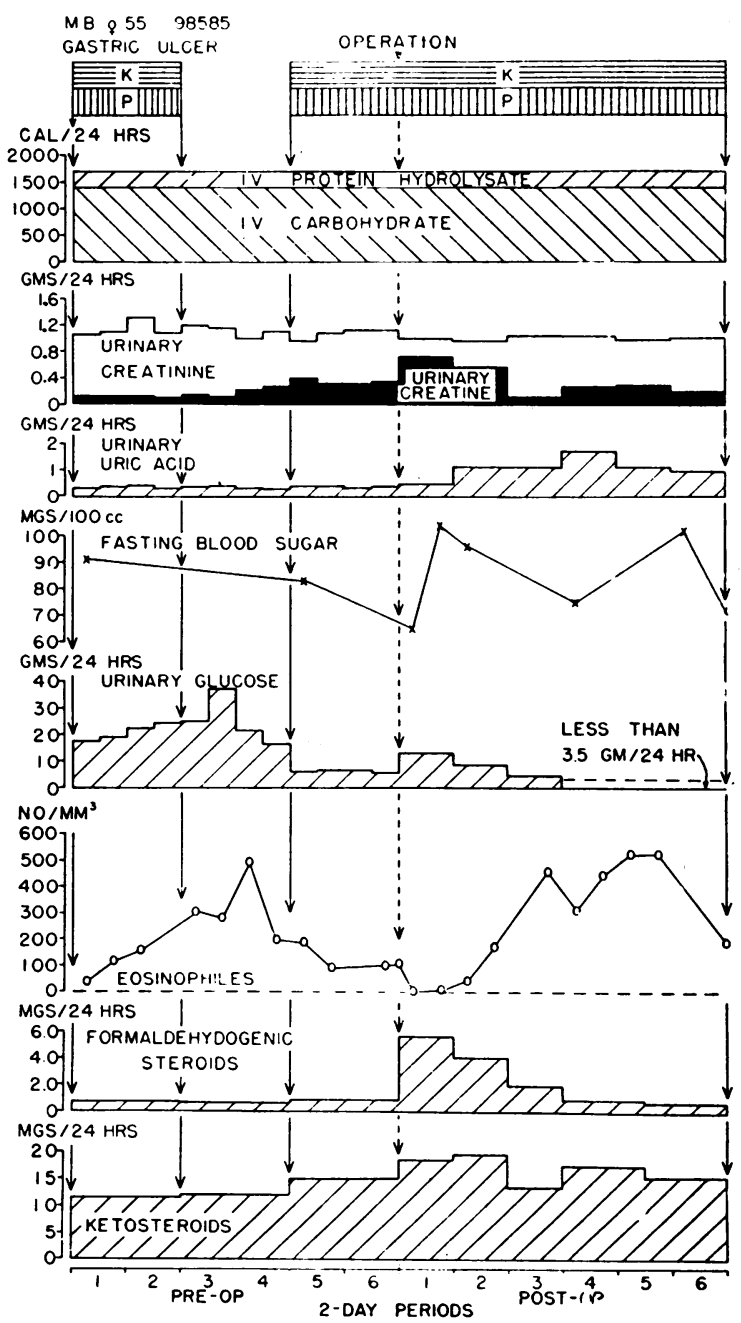

Fig. 8. Case 2. The Effects of Potassium ano Phosphores Deprivation and Operative Trauma on the Urinary Crfatine, Crfatinine, Uric Acid, Glucose, Formaldenimosexic Steroid, and Ketosteroid Excretion: AND ox the Fasting Biono Giducose and Eosinophile Concentrations 
cident with a marked rise in formaldehydogenic steroids and a slight elevation of the ketosteroids (Figure 8).

\section{DISCUSSION}

The postoperative eosinopenia and rise in urinary steroid excretion which occurred in these patients can be interpreted as eviclence of increased adrenal cortical function. We have previously pointed out that the muscular weakness and hypopotassemia, hypochloremia, and metabolic alkalosis exhibited by certain postoperative patients bear a striking resemblance to the findings in patients with Cushing's syndrome (spontaneous hyperadrenocorticism) (12). Similarly, in patients in whom hyperadrenocorticism was induced by administration of ACTH or cortisone, we have observed, just as in cases 1 and 2, losses of nitrogen ; intracellular depletion of potassium and phosphorus; the development of metabolic alkalosis, hypopotassemia and hypochloremia; rises in urinary creatine, uric acid, and steroids; and eosinopenia (3). Significant tissue deficits of potassium and phosphorus were also demonstrated both in a patient with Cushing's syndrome and in patients who had received ACTH or cortisone (4). It appears, therefore, that the postoperative metabolic changes could be accounted for by increased arlrenal cortical function.

On the other hand, provision of potassium ion in case 1 was accompanied by diminished losses of nitrogen, phosphorus, potassium and creatine, suggesting that potassium deprivation may have played an important role in these losses. There is evidence that administration of potassium will reduce nitrogen loss in rats (13) or humans (14) receiving ACTH, or in patients with Cushing's syndrome (5).

When potassium and phosphorus were omitted, however, in case 2 prior to surgery, there was no significant change in the nitrogen balance. In a study reported elsewhere (3) in which a patient was maintained on an artificial potassium-free liet for 18 days, the maximum daily potassium loss was 29.9 meq. and no negative nitrogen balance resulted. The results inclicate that short periods of potassium deprivation in the adult human do not cause nitrogen loss.

Potassium deprivation in case 2 produced a maximum daily loss of 38.1 meq. of potassium in excess of that expected from the nitrogen balance. A maximum daily postoperative loss of $85.7 \mathrm{meq}$. was observed, however, in case 1 . The largest daily loss of potassium in excess of nitrogen, reported by several observers, in subjects on potassium-free intakes was 55 meq. $(3,15-17)$. Potassium losses following traumatic procedures vary widely but sometimes exceed this figure by substantial amounts, with losses up to 110 meq. in excess of nitrogen having been reported (18). It is evident that operative trauma in case 2 resulted in a marked increase in urinary potassium and a small intracellular potassium loss in spite of a constant potassium intake.

During the period of potassium phosphate deprivation in case 2 there was no significant increase in urinary creatine, uric acid or steroid excretion, nor any fall in eosinophile concentration. It seems unlikely, therefore, that the lack of these two ions

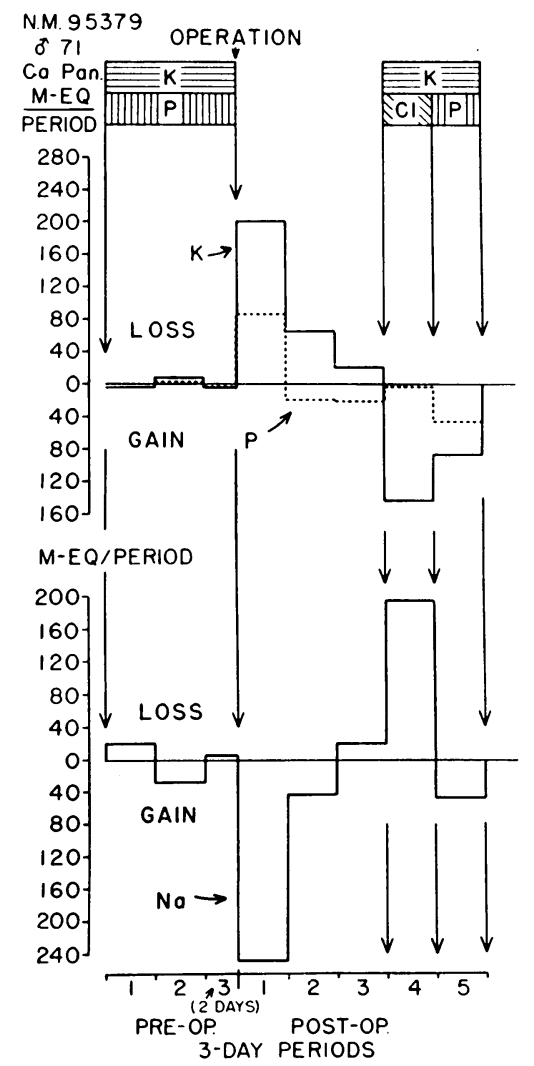

Fig. 9. Case 1. The Ehects of Operative Trauma ani Putassica and Piosphorus Deprivation on the Intrachililar Balanchs of Potassium, Phosphores, AnI SomIIn 
could entirely account for the metabolic changes observed postoperatively.

Following the operation in case 2, most of the metabolic changes seen in case 1 were duplicated, though they were in general of shorter duration and lesser magnitude. It is thus apparent that even though the potassium and phosphorus intakes were maintained, trauma resulted in the production of changes similar to those seen in hyperadrenocorticism.

The suggested sequence of events is that as a result of trauma, the pituitary produces more ACTH which in turn causes increased production of adrenal cortical steroids. The latter, either through effects on tissues, the kidney, or both, causes the described metabolic changes.

Some evidence indicates, however, that adrenal cortical hyperfunction is not necessarily associ-

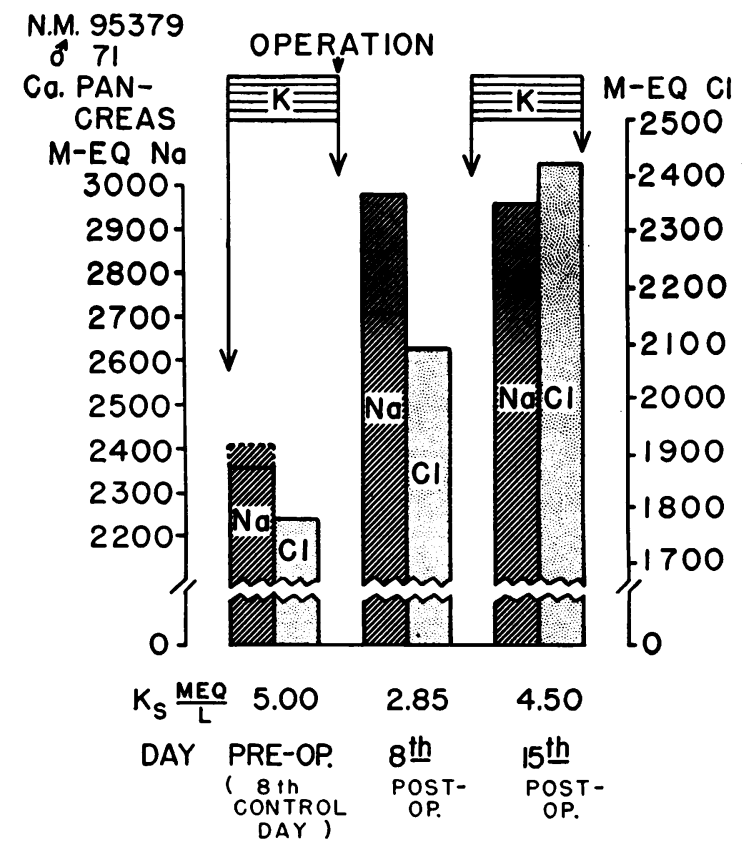

Fig. 10. Case 1. The Effects of Operative Trauma and Potassium and Phosphorus Deprivation on the Sodium and Chloride Contents of the Sodium and Bromide Spaces, Respectively

The chart is so constructed that equal heights of the paired columns represent the existence of sodium and chloride ions at their approximately normal concentration ratio of $1.26: 1$ in extracellular water. The broken lines represent the amount of sodium that could be accommodated in the simultaneously found bromide space at the existing concentration of sodium in extracellular water. Corresponding serum potassium concentrations are given below each determination.

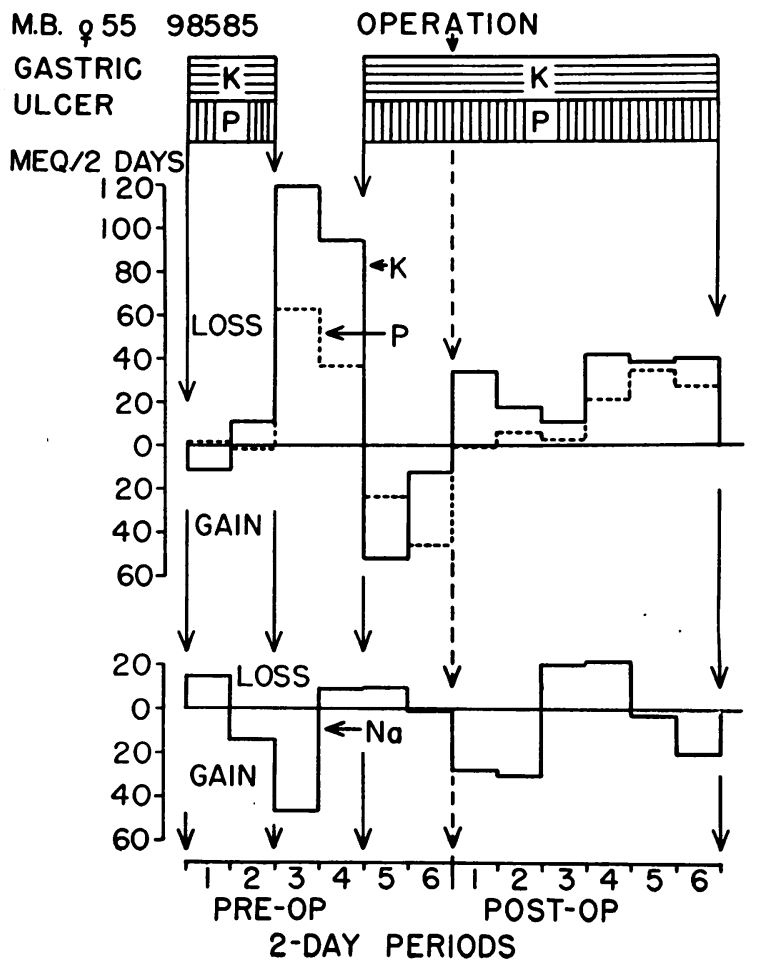

Fig. 11. Case 2. The Effects of Potassium and Phosphorus Deprivation and of Operative Trauma on the Intracellular Balances of Potassium, PhosPHORUS, AND SODIUM

ated with the post-traumatic "catabolic response." Stressed, adrenalectomized rats maintained with cortin or cortisone still exhibit a "catabolic response" as measured by non-protein nitrogen excretion (19) or blood urea nitrogen production (20). It has not been determined in the human, however, whether the metabolic changes, noted in the postoperative patients, would occur in the absence of adrenal cortical hyperfunction.

Werner, Habif, Randall, and Lockwood (21) have proposed that the nitrogen loss which occurs postoperatively is due to the reduction in caloric intake usually incident to an operative procedure. In the experiments reported here a constant caloric and protein intake was maintained pre- and postoperatively. This intake may, however, have become inadequate to meet the requirements of the injured or stressed organism. The moderate postoperative temperature elevation encountered in case 1 may also have contributed to a caloric deficit by increasing caloric expenditure. No significant postoperative temperature eleva- 
tion occurred in case 2, however, in whom there was nevertheless a definite "catabolic response." Doubling the dietary intake of a patient receiving ACTH will abolish markedly negative balances of nitrogen, phosphorus, and potassium and incleed cause retention of these elements (3). The protein catabolic response to stress in the rat can also be abolished by the administration of glucose or amino acids (22), or reduced by the administration of potassium (13). These olservations suggest the possibility of abolishing post-traumatic metabolic changes if high enough intakes of calories, protein, and intracellular electrolytes could be achieved.

The high intravenous glucose intake was equivalent to a daily glucose tolerance test ; normal preoperatively in case 1. but demonstrating. postoperatively, gradually increasing glycosuria and hyperglycemia. These manifestations, however. disappeared promptly when the glucose intake was reduced to normal at the termination of parenteral feeding. It seems unlikely that removal of the head of the pancreas could entirely account for these events; or that adrenal cortical hyperfunction could be implicated, since activity of the adrenal cortex appeared to be subsiding while the diabetic state was becoming worse. The increasing glycosuria correlates directly, however. with the cumulative intracellular potassium deficit (Table I). A relationship between potassium and carbohydrate metabolism has been demonstrated in a numher of experimental studies. Bennett. Whitney, and Glafkides (13) have shown that potassium, given to partially depancreatized rats receiving ACTH, will reduce the glycosuria ; and Gardner and associates (23) have demonstrated diabetic glucose tolerance curves in rats subjected to prolonged potassium deficit: Hastings, Teng. Neshett, and Sinex have demonstrated that liver slices incubated in a medium containing a high concentration of potassium (110 meq./L.) show less glucose formation from pyruvate and more glucose uptake than do slices incubated in a medium with a low concentration of potassium ( 5 meq./L.). Glycogen formation from both glucose and pyruvate is higher in the high potassium medium than in the low potassium medium (24). It has furthermore been shown that potassium is necessary for the formation of phosphopyruvate, an intermediary in the carbohydrate cycle, and source of high energy phosphate bonds (25).

Thus it seems reasonable to suggest that potassium deficit could have resulted in impaired glucose utilization, and increased glycogenolysis and gluconeogenesis. No significant reduction in glycosuria occurred when potassium was added, but the marked retention of potassium in excess of that expected from the nitrogen balance during this period indicates that insufficient potassium had been retained, even at the end of the study, to repair the deficit (see also Table I).

Slight reduction in glycosuria coincided with addition of phosphate ion. One is inclined to speculate whether the phosphorus deficit resulted in impaired phosphorylating mechanisms and decreased glucose utilization. Two facts against this view are: 1) the balance data which indicate that repair of the intracellular phosphorus deficit had already occurred at the peak of the diabetes and 2) the tissue analysis, taken before phosphate was restored, which showed no decrease in phosphorus content.

Deprivation of phosphate ion in each case resulted in stepwise increases of urinary calcium excretion until the intracellular phosphate deficit was repaired. Provision of phosphate ion in each instance resulted in a prompt drop of urinary calcium. Increased calcium excretion due to immobilization seems unlikely, since moderate and uniform activity was maintained throughout each study, except for the immediate postoperative period.

\section{SUMMARY AND CONCLUSIONS}

1. The metabolic effects resulting from operative trauma and from potassium and phosphorus deprivation have been observed in two patients. During the postoperative period one of the patients received no potassium or phosphorus, while the other received optimal amounts of these elements. The patients were maintained on constant caloric and protein intakes.

2. Similar metabolic changes were observed in each patient postoperatively, though more pronounced in the patient who received no potassium or phosphorus. These changes were: $a$ ) loss of protoplasm as shown by negative balances of nitrogen, phosphorus, and potassium, $b$ ) intracellular depletion of potassium and phosphorus, $c$ ) 
development of metabolic alkalosis and hypochloremia, $d$ ) eosinopenia, and $e$ ) increased urinary excretion of uric acid, creatine, formaldehydogenic steroids and ketosteroids.

3. These changes bear a striking resemblance to those seen in patients with hyperadrenocorticism, whether spontaneous or induced by $\mathrm{ACTH}$ or cortisone.

4. A preoperative period of potassium and phosphorus deprivation in one of the patients resulted in intracellular losses of these elements but failed to produce increased nitrogen loss or any evidence of increased adrenal cortical function.

5. In spite of substantial and constant intakes of potassium and phosphorus, operative trauma in case 2 resulted in marked increases in urinary content, and in intracellular losses, of these elements.

6. These findings suggest that a post-traumatic increase in adrenal cortical steroid production resulted in the metabolic changes observed. However, it has not been established whether similar changes with respect to nitrogen and the electrolytes would occur post-traumatically in the absence of a hyperadrenocortical state.

7. A possible relationship between postoperative potassium deficit and the development of a diabetic state in one of the patients is discussed.

8. A prompt rise in urinary calcium excretion was observed during phosphorus deprivation, indicating that in the presence of intracellular phosphorus deficit, decalcification of bone provides a small amount of phosphorus for repair purposes.

\section{ACKNOWLEDGMENTS}

The authors gratefully acknowledge helpful criticism of the manuscript by Dr. Henry T. Randall and the assistance of Milton Grossman, research fellow; Sophie Rys, Rhea Neznek, Albina Foster, Olive Pike, nurses; Edna Block, Ann Spilka, research assistants; Bernice Katz, Constance Ryder, Marguerite Oliver, technicians; and Bess Lande, cartographer.

\section{REFERENCES}

1. Eliel, L. P., Pearson, O. H., and Rawson, R. W., Postoperative potassium deficit and metabolic alkalosis. New England J. Med., 1950, 243, 471 and 518.

2. Sprague, R. G., Power, M. H., Mason, H. L., Albert, A., Mathieson, D. R., Hench, P. S., Kendall, E. C.. Slocumb, C. H., and Polley, H. F., Observations on the physiologic effects of cortisone and ACTH in man. Arch. Int. Med., 1950, 85, 199.

3. Pearson, O. H., and Eliel, L. P., Experimental studies with ACTH and cortisone in patients with neoplastic disease; in Recent Progress in Hormone Research, edited by Pincus, G. Academic Press, New York, 1951, Vol. VI, p. 373.

4. Eliel, L. P., Hellman, L., Pearson, O. H., and Katz, B., The effects of ACTH on the electrolyte content of various body tissues; in Proceedings of the Second Clinical ACTH Conference, Vol. I, Research; edited by Mote, J. R. Blakiston Co., Philadelphia, 1951, p. 196.

5. Eliel, L. P., and Pearson, O. H., The metabolic effects of adrenocorticotropic hormone (ACTH) in a patient with Cushing's syndrome and acromegaly. J. Clin. Endocrinol., 1951, 11, 913.

6. Brodie, B. B., and Friedman, M. M., Determination of bromide in tissues and biological fluids. J. Biol. Chem., 1938, 124, 511.

7. Peters, J. P., and Van Slyke, D. D., Quantitative Clinical Chemistry, Vol. II, Methods. Williams \& Wilkins Co., Baltimore, 1932, p. 558.

8. Reifenstein, E. C., Jr., Albright, F., and Wells, S. L., The accumulation, interpretation, and presentation of data pertaining to metabolic balances, notably those of calcium, phosphorus, and nitrogen. J. Clin. Endocrinol., 1945, 5, 367.

9. Bartter, F. C., Fourman, P., Albright, F., Forbes, A. P., Jefferies, W. McK., Griswold, G., Dempsey, E., Bryant, D., and Carroll, E., The effect of adrenocorticotropic hormone in panhypopituitarism. J. Clin. Invest., 1950, 29, 950.

10. Steele, J. M., Berger, E. Y., Dunning, M. F., and Brodie, B. B., Total body water in man. Am. J. Physiol., 1950, 162, 313.

11. Shohl, A. T., Mineral Metabolism. Am. Chem. Soc. Monograph Series, Reinhold Publishing Corp., New York, 1939.

12. Pearson, O. H., and Eliel, L. P., Postoperative alkalosis and potassium deficiency. J. Clin. Invest., 1949, 28, 803.

13. Bennett, L. L., Whitney, J. E., and Glafkides, C., Modification of the metabolic effects of adrenocorticotropic hormone and growth hormone by the administration of a diet high in potassium chloride. J. Clin. Endocrinol., 1950, 10, 826.

14. Pearson, O. H., Eliel, L. P., and Rawson, R. W., Regression of lymphoid tumors in man induced by ACTH and cortisone; in Proceedings of the First Clinical ACTH Conference; edited by Mote, J. R. Blakiston Co., Philadelphia, 1950, p. 318.

15. Gamble, J. L., Physiological information gained from studies on the life raft ration. Harvey Lect., 1947, 42, 247.

16. Tarail, R., and Elkinton, J. R., Potassium deficiency and the role of the kidney in its production. J. Clin. Invest., 1949, 28, 99. 
17. Randall, H. T., Habif, D. V., Lockwood, J. S., and Werner, S. C., Potassium deficiency in surgical patients. Surgery, 1949, 26, 341.

18. Howard, J. E., and Bigham, R. S., Jr., Movement of potassium during the protein catabolic reaction after trauma. Tr. of Tenth Conf. on Metabolic Aspects of Convalescence. Josiah Macy., Jr. Founclation, New York, 1945, pp. 272-302.

19. Ingle, D. J., Some studies on the role of the adrenal cortex in organic metabolism. Ann. New York Acad. Sc., 1949, 50, 576.

20. Engel, F. L., Comparative effects of ACTH and stress in nitrogen metabolism: in Proceedings of the Second Clinical ACTH Conference, Vol. I, Research; edited by Mote, J. R. Blakiston Co., Philadelphia, 1951, p. 235.

21. Werner, S. C., Habif, D. V., Randall, H. T., and Lockwood, J. S., Postoperative nitrogen loss: A comparison of the effects of trauma and of caloric readjustment. Ann. Surg., 1949, 130, 688.

22. Engel, F. L., A consideration of the roles of the adrenal cortex and stress in the regulation of protein metabolism; in Recent Progress in Hormone Research, edited by Pincus, G. Academic Press, New York, 1951, Vol. VI., p. 277.

23. Gardner, L. I., Talbot, N. B., Cook, C. D., Berman, H., and Concepcion, L. R., The effect of potassium deficiency on carbohydrate metabolism. J. Lab. \& Clin. Med., 1950, 35, 592.

24. Hastings, A. B., Teng, C. T., Nesbett, F. B., and Sinex, F. M., Studies on carbohydrate metabolism in rat liver slices. I. The effect of cations in the media. J. Biol. Chem., 1952, 194, 69.

25. Lardy, H. A., and Ziegler, J. A., The enzymatic synthesis of phosphopyruvate from pyruvate. J. Biol. Chem., 1945, 159, 343. 